\title{
HUBUNGAN PENGAWASAN ORANG TUA DAN MEDIA \\ INFORMASI TERHADAP PERILAKU SEKSUAL PRANIKAH PADA REMAJA
}

\author{
Hamzah B ${ }^{1 *}$, Hamzah, St. Rahmawati ${ }^{2}$ \\ ${ }^{1}$ Program Studi S1 Kesehatan Masyarakat, STIKES Graha Medika \\ ${ }^{2}$ Program Studi D III Kebidanan, STIKES Graha Medika \\ *Korespondensi : hamzahbskm@gmail.com
}

\begin{abstract}
Background: Premarital sexual behavior is one of the result of promiscuity. This problem tends to be carried out by middle adolescent groups (15-18 years). Around $63 \%$ of junior high school, high school and university-age adolescents in Indonesia claimed to have had premarital sex. Some permissive dating behaviors performed by adolescents include holding hands when dating (92\%), kissing (82\%), and petting $(63 \%)$. Purpose: This purpose ostudy aims to determine the relationship of parental supervision and information media with premarital sexual behavior in adolescents at State High School No 1 Kotamobagu. Method: This study applied an analytic cross-sectional design with a sample of 299 school-age adolescents aged 14-18 years. The sampling technique used was stratified random sampling. Data were collected by direct interviews with respondents and analyzed univariately and bivariately using the chi square test. Results: The results of the study based on the chi square test showed that there was a relationship between parental supervision $(\mathrm{p}=0.006)$ and information media $(\mathrm{p}=0.001)$ with premarital sexual behavior in adolescents. Conclusion: There was a relationship between parental supervision and information media with sexual behavior in adolescents at State High School No 1 Kotamobagu. It is recommended to the relevant parties to play an active role in conducting supervision and providing sexual education early on so that students avoid premarital sexual behavior.
\end{abstract}

Keywords: Information Media; Parental Supervision; Premarital Sexual Behavior

\begin{abstract}
ABSTRAK
Latar bealakang: Perilaku seksual pranikah merupakan salah satu akibat dari pergaulan bebas. Permasalahan ini cenderung dilakukan oleh kelompok remaja tengah (15-18 tahun). Sekitar 63\% remaja usia sekolah SMP, SMA dan mahasiswa di Indonesia mengaku sudah pernah melakukan hubungan seks pranikah. Beberapa perilaku pacaran permisif yang dilakukan oleh remaja antara lain berpegangan tangan saat pacaran $(92 \%)$, berciuman $(82 \%)$, rabaan petting $(63 \%)$. Tujuan: Tujuan penelitian ini untuk mengetahui hubungan pengawasan orang tua dan media
\end{abstract}

Jurnal Kesehatan Medika Zdayana Vol.06 No.01 April 2020 Page 42 
informasi dengan perilaku seksual pranikah pada remaja di SMAN 1 Kotamobagu. Metode: Penelitian ini menggunakan design cross sectional analitik dengan jumlah sampel 299 remaja sekolah umur 14-18 tahun. Teknik penarikan sampel yang digunakan adalah stratified random sampling. Data dikumpulkan dengan wawancara langsung kepada responden dan dianalisis secara univariat dan bivariat dengan menggunakan uji chi square. Hasil: Berdasarkan hasil penelitian diperoleh responden yang memiliki perilaku seksual pranikah berisiko sebanyak 31,1\%, dan yang tidak berisiko sebanyak $68,9 \%$ responden. Responden yang mempunyai pengawasan orang tua kurang sebanyak $41,1 \%$, dan yang baik sebanyak 58,9\% responden, sedangkan responden yang memperoleh media informasi negatif sebanyak $45,8 \%$, dan yang positif sebanyak $54,2 \%$ responden. Hasil uji chi square menunjukkan bahwa, ada hubungan pengasawan orang tua $(p=0,006)$ dan media informasi $(\mathrm{p}=0,001)$ dengan perilaku seksual pranikah pada remaja. Simpulan: Ada hubungan pengawasan orang tua dan media informasi dengan perilaku seksual pada remaja SMAN 1 Kotamobagu. Disarankan kepada pihak terkait untuk berperan aktif didalam melakukan pengawasan dan memberikan pendidikan seksual sejak dini agar siswa terhindar dari perilaku seksual pranikah.

Kata Kunci: Pengawasan Orang Tua; Media Informasi; Perilaku Seksual Pranikah

\section{PENDAHULUAN}

Perilaku seksual pranikah merupakan salah satu akibat dari pergaulan bebas. Permasalahan ini cenderung dilakukan oleh kelompok remaja tengah (15-18 tahun) merupakan masa-masa ingin mencari identitas diri, tertarik dengan lawan jenis, timbul perasaaan cinta dan mulai berkhayal mengenai hal-hal yang berkaitan dengan seksual. Remaja akhir (19-21 tahun) merupakan remaja yang mengungkapkan kebebasan diri dan mewujudkan perasaan cinta yang dirasakannya (Kemenkes RI, 2015).

Data menunjukkan bahwa remaja usia sekolah SMP, SMA dan mahasiswa di Indonesia mengaku pernah melakukan hubungan seksual pranikah sekitar 63\%, data itu merupakan hasil survei dari sampel 33 di provinsi di Indonesia pada tahun 2008. Data survei terakhir Badan Koordinasi Keluarga Berencana Nasional (BKKBN) pada tahun 2010 menyebutkan sebanyak 5.912 wanita di umur 15-19 tahun secara nasional pernah melakukan hubungan seksual. Beberapa perilaku pacaran permisif yang dilakukan oleh remaja antara lain berpegangan tangan saat pacaran (92\%), berciuman (82\%), petting (63\%) (BKKBN, 2012). 
Data survei RPJMN Remaja dari tahun 2012-2014 di Sulawesi Utara dengan sampel remaja yang berumur 15-24 tahun diperoleh sebanyak 90\% remaja yang berpacaran pernah berpegangan tangan, sementara remaja yang berpacaran mengaku pernah ciuman bibir sebanyak 59\%. Data BKKBN menunjukkan angka penurunan dibanding tahun 2013 yakni 63\%. Namun, jika dibandingkan data tahun 2012 data remaja yang pernah berciuman bibir masih tinggi sebanyak 39\%. Aktivitas ini sangat berbahaya bagi remaja karena perilaku tersebut dapat menjadi pintu masuk remaja untuk melakukan perilaku seksual di luar pernikahan (Agung, 2016).

Beberapa faktor yang berperan terhadap aktifitas perilaku seksual pranikah remaja adalah pengawasan orang tua dan media informasi, namun media informasi beberapa penelitian menemukan hasil yang berbeda. Penelitian di MA Darul Arqam dengan jumlah sampel sebanyak 79 santri, menemukan bahwa ada pengaruh peran orang tua di MA Darul Arqam $(\mathrm{p}=0,000, \varphi=0,403)$ terhadap perilaku seksual berisiko santri (Masni, 2018). Penelitian lain di SMA Negeri 1 Indralaya Utara dengan sampel 165 siswa menemukan ada hubungan pengaruh orang tua ( $\mathrm{p}$ value =0,030; PR 2,292: 95\% CI 1,135-4,626) terhadap perilaku seksual pranikah (Anissa Nurhayati, Nur Alam Fajar, 2017). Hasil penelitian di SMKN 1 Kendari dengan sampel 90 siswa, menemukan ada hubungan yang signifikan antara akses media informasi ( $\mathrm{p}$ value $=0,001$ ) siswa dengan perilaku seksual (Harni Andriani, Yasnani, 2016). Hasil yang sama diperoleh pada penelitian yang dilakukan di SMAN 3 Bantul DIY dengan jumlah sampel 126 siswa, menemukan ada hubungan antara pengaruh media informasi dengan perilaku seks pranikah remaja $(\mathrm{p}=0,177>0,05)$ (Wijayan, 2019).

Tujuan penelitian ini adalah untuk mengetahui apakah ada hubungan antara pengawasan orang tua dan media informasi terhadap perilaku seksual pranikah remaja di SMAN 1 Kotamobagu.

\section{METODE}

Jenis penelitian yang digunakan adalah observasional analitik dengan rancangan cross sectional study dengan lokasi penelitian di SMAN 1 Kotamobagu 
dan waktu penelitian pada bulan Februari 2020. Sampel pada penelitian ini adalah remaja SMAN 1 Kotamobagu berusia 14-18 tahun sebanyak 299 siswa. Teknik penarikan sampel yang digunakan adalah stratified random sampling yaitu cara penarikan sampel dengan memperhatikan strata (tingkatan) didalam populasi (Notoatmodjo, 2012). Data dikumpulkan menggunakan dua cara yakni data primer dilakukan wawancara langsung kepada responden dan data sekunder berupa jumlah siswa di SMAN 1 Kotamobagu. Data dianalisis secara univariat dan bivariat dengan menggunakan uji chi square.

\section{HASIL}

Berdasarkan hasil analisis univariat pada tabel 1 diperoleh umur responden paling banyak umur 16 tahun sebanyak 121 responden (50,5\%) dan yang paling terendah adalah umur 14 tahun sebanyak 10 responden $(3,3 \%)$. Jenis jenis kelamin responden paling banyak adalah perempuan sebanyak 202 responden $(67,6 \%)$, dan yang paling terendah adalah laki-laki sebanyak 97 responden $(32,4 \%)$. Hasil yang diperoleh pada variabel perilaku seksual pranikah berisiko sebanyak $93(31,1 \%)$, dan yang tidak berisiko sebanyak 206 responden (68,9\%). Responden yang mempunyai pengawasan orang tua kurang sebanyak $123(41,1 \%)$, dan yang baik sebanyak 176 responden $(58,9 \%)$, sedangkan responden yang mempunyai media informasi negatif sebanyak 137 (45,8\%), dan yang positif sebanyak 162 responden $(54,2 \%)$.

Tabel 1 Distribusi Responden Berdasarkan Umur, Jenis Kelamin, Perilaku Seksual Pranikah, Pengawasan Orang Tua dan Media Informasi

\begin{tabular}{ccc}
\hline Karakteristik & Jumlah (n) & Presentase (\%) \\
\hline Umur (Tahun) & 10 & 3,3 \\
\hline 14 & & \\
\hline \multicolumn{4}{c}{ Jurnal Kesehatan Medika Udayana Vol.06 No.01 April 2020} & Dage 45
\end{tabular}




\begin{tabular}{ccc}
15 & 67 & 22,4 \\
16 & 121 & 40,5 \\
17 & 89 & 29,8 \\
18 & 12 & 4,0 \\
\hline Jenis Kelamin & \\
Laki-laki & 97 & 32,4 \\
Perempuan & 202 & 67,6 \\
\hline Perilaku Seksual Pranikah & & \\
Berisiko & 93 & 31,1 \\
Tidak Berisiko & 206 & 68,9 \\
\hline Pengawasan Orang Tua & 123 & 41,1 \\
Kurang & 176 & 58,9 \\
Baik & & \\
Media informasi & 137 & 45,8 \\
Negatif & 162 & 54,2 \\
Positif & 299 & 100
\end{tabular}

Sumber: Data Primer, 2020

Tabel 2 Analisis Bivariat Determinan Perilaku Seksual Pranikah

\begin{tabular}{ccccc}
\hline Variabel & Berisiko & Tidak Berisiko & Total & Nilai \\
\cline { 2 - 4 } & $\mathbf{n}(\boldsymbol{\%})$ & $\mathbf{n}(\boldsymbol{\%})$ & $\mathbf{n}(\boldsymbol{\%})$ & $\boldsymbol{p}$ \\
\hline Pengawasan orang tua & & & & \\
Kurang & $49(39,8)$ & $74(60,2)$ & $123(100)$ & 0,006 \\
Baik & $44(25)$ & $132(75)$ & $176(100)$ & \\
\hline $\begin{array}{c}\text { Media informasi } \\
\text { Negatif }\end{array}$ & $58(42,3)$ & $79(57,7)$ & $137(100)$ & 0,000 \\
Positif & $35(21,6)$ & $127(78,4)$ & $162(100)$ & \\
\hline
\end{tabular}

Sumber: Data Primer, 2020

Hasil penelitian pada tabel 2, menunjukkan dari 123 responden yang mempunyai pengawasan orang tua kurang terdapat $49(39,8 \%)$ responden yang mempunyai perilaku seksual pranikah berisiko dan $74(60,2 \%)$ responden yang mempunyai perilaku seksual pranikah tidak berisiko, sedangkan dari 176 responden yang mempunyai pengawasan orang tua baik terdapat $44(25,0 \%)$ responden yang mempunyai perilaku seksual berisiko. Hasil uji stastistik dengan menggunakan uji Chi Square didapatkan nilai probabilitas $(\mathrm{p}=0,006)$. Karena nilai $\mathrm{p}<0,05$ maka ada hubungan antara pengasawan orang tua dengan perilaku seksual pranikah pada remaja SMAN 1 Kotamobagu. Variabel media informasi hasil penelitian menunjukkan dari 137 responden yang memperoleh media informasi negatif 
terdapat $58(42,3 \%)$ responden yang mempunyai perilaku seksual pranikah berisiko, sedangkan dari 162 responden yang memperoleh media informasi positif terdapat $35(21,6 \%)$ responden yang mempunyai perilaku seksual berisiko. Hasil uji stastistik dengan menggunakan uji Chi Square didapatkan nilai probabilitas (p $=0,000)$. Karena nilai $\mathrm{p}<0,05$ maka ada hubungan antara media informasi dengan perilaku seksual pranikah pada remaja SMAN 1 Kotamobagu.

\section{PEMBAHASAN}

Penelitian ini bertujuan untuk mengetahui hubungan antara pengawasan orang tua dan media informasi dengan perilaku seksual pranikah pada remaja SMAN 1 Kotamobagu. Responden dalam penelitian ini adalah siswa kelas X, XI, dan XII yang berumur 14-18 tahun. SMAN 1 Kotamobagu merupakan salah satu sekolah negeri yang terletak di Kelurahan Biga Kecamatan Kotamobagu Utara Kota Kotamobagu dengan akreditasi A (Amat Baik). Jumlah keseluruhan siswa SMAN 1 Kotamobagu yaitu 1.195 siswa.

Pada variabel pengawasan orang tua diperoleh hasil yang menunjukkan ada hubungan antara pengawasan orang tua dengan perilaku seksual pranikah pada remaja SMAN 1 Kotamobagu $(\mathrm{p}=0,006)$. Didapatkan dari 176 responden yang mempunyai pengawasan orang tua baik, terdapat $44(25,0 \%)$ responden yang mempunyai perilaku seksual pranikah berisiko. Perilaku ini disebabkkan masih ada $54,2 \%$ orang tua yang marah kepada anak, jika bertanya tentang hubungan seksual, $25,0 \%$ orang tua yang membiarkan bila ada lawan jenis atau pacar anak masuk di dalam kamar, dan 34,8\% orang tua yang membolehkan anak pergi berdua degan lawan jenis atau pacar. Berdasarkan data ini terlihat bahwa orang tua masih kurang pengawasan terhadap anaknya terkait dengan siapa anaknya bergaul dan bagaimana perilaku anaknya dirumah dengan lawan jenis atau pacarnya. Upaya promotif dan preventif yang dapat dilakukan untuk permasalahan seksual remaja, salah satunya dengan pendidikan seksual. Pendidikan seksual idealnya diberikan pertama kali oleh orangtua di rumah, mengingat yang paling tahu keadaan anak adalah orangtua sendiri. 
Penelitian ini sejalan dengan penelitian yang dilakukan di SMAN 1 Jamblang dengan jumlah sampel sebanyak 268 siswa, menemukan terdapat hubungan yang bermakna antara peran orang tua dengan perilaku seksual pra nikah remaja ( $\rho=0,004)$ (Nina Nirmaya Mariani, 2018). Penelitian lain di SMK Negeri 1 Sedayu dengan sampel 78 siswa menemukan ada hubungan yang signifikan antara peran orang tua dengan peilaku seksual pranikah remaja di SMKN 1 Sedayu dengan nilai $\mathrm{p}=0,000(\mathrm{p}<0,05)$ dengan keeratan hubungan yang lemah sebesar $\mathrm{r}=0,399$ (Diah Suci Haryani, Wahyuningsih, 2016).

Pada variabel media informasi diperoleh hasil yang menunjukkan ada hubungan antara media informasi dengan perilaku seksual pranikah pada remaja SMAN 1 Kotamobagu $(\mathrm{p}=0,000)$. Didapatkan dari 162 responden yang memperoleh media informasi positif terdapat $35(21,6 \%)$ responden yang mempunyai perilaku seksual berisiko. Disebabkan masih ada $8,4 \%$ responden yang biasa melakukan hubungan seks pranikah setelah melihat film porno, terdapat $37,1 \%$ responden yang mengikuti tren dan gaya pacaran dari tayangan-tayangan TV, dan masih ada 18,4\% responden yang tidak pernah mendapatkan pengetahuan seputar seksualitas dan reproduksi di sekolah, dan $25,4 \%$ responden yang tidak pernah mendapatkan bimbingan konseling seputar kesehatan seksual dari guru-guru bimbingan konseling di sekolah. Hasil wawancara diperoleh ada beberapa siswa yang biasa menonton video porno dari youtube diinternet melalui handphone yang berhubungan dengan perilaku seksual. Selain itu masih terdapat pula beberapa siswa yang membawa handphone disekolah sehingga siswa dapat dengan mudah mengakses internet. Selain itu, siswa dapat dengan mudah mengakses media informasi diluar rumah tanpa pengawasan dari guru dan orang tua.

Hasil penelitian ini didukung oleh penelitian yang dilakukan di SMA AnNaas dengan jumlah sampel 94 orang, menemukan adanya hubungan keterpaparan media massa dengan tindakan seksual dimana nilai p value 0,000 (Istawati, 2017). Penelitian lain di SMKN 10 Surabaya dengan sampel sebanyak 89 orang, menemukan ada hubungan antara paparan media pornografi $(\mathrm{p}=0,000)$ dengan perilaku seksual pranikah pada remaja (Albertus C, Dimas Pratama, 2017). Paparan media pornografi memiliki dampak yang buruk bagi remaja yang akhirnya berujung 
pada perilaku seks bebas. Perilaku seks bebas memiliki urutan paling ringan hingga berat dan sering dilakukan remaja ketika berpacaran (R \& W, 2018). Berdasarkan tahapannya, perilaku seksual dalam berpacaran dimulai dari tahapan kissing, necking, petting dan intercourse. Saat ini banyak film yang memiliki adegan berciuman yang ditonton oleh remaja dan akhirnya penasaran ingin mencoba hal tersebut, perilaku yang dimulai dari berciuman kemudian dalam waktu yang lama akan terbiasa sehingga akan berlanjut ketahapan selanjutnya seperti necking, petting dan intercourse (Parkes et al., 2014).

Penelitian ini memiliki keterbatasan adalah untuk masing-masing variabel penelitian diukur dengan menggunakan kuesioner (tidak diobservasi) sehingga jawaban yang diperoleh sangat bergantung pada kebenaran jawaban yang diberikan responden.

\section{SIMPULAN DAN SARAN}

Kesimpulan penelitian ini adalah ada hubungan antara pengasawan orang tua dengan perilaku seksual pranikah pada remaja SMAN 1 Kotamobagu tahun 2020, dan ada hubungan antara media informasi dengan perilaku seksual pranikah pada remaja SMAN 1 Kotamobagu tahun 2020.

Disarankan kepada pihak terkait seperti orang tua, guru, dan tenaga kesehatan untuk lebih aktif melakukan pengawasan terhadap perilaku anak remaja sekolah tentang seksual pranikah dengan memberikan pendidikan seksual sejak dini dan melakukan bimbingan atau konseling terkait dengan permasalahan seksual pada remaja. Bagi peneliti selanjutnya dapat menambah literatur dengan meneliti faktor lain yang berhubungan dengan perilaku seksual pranikah pada remaja seperti pemahaman tentang agama, peran lingkungan sekolah, peran tokoh masyarakat dan lain sebagainya.

\section{DAFTAR PUSTAKA}

Agung. (2016). Keperjakaan dan Keperawanan Generasi Milineal. https://tirto.id/keperjakaan-dan-keperawanan-generasi-milenial-bEYw

Albertus C, Dimas Pratama, H. B. N. (2017). Analisis Hubungan Pergaulan dengan Teman dan Paparan Media Pornografi terhadap Perilaku Seksual Pranikah pada Remaja. 
Jurnal Biometrika Dan Kependudukan, 6(1), 1-8. https://ejournal.unair.ac.id/JBK/article/viewFile/5273/pdf

Anissa Nurhayati, Nur Alam Fajar, Y. (2017). Determinan perilaku seksual pranikah pada remaja SMA Negeri 1 Indralaya Utara. Jurnal Ilmu Kesehatan Masyarakat, 8(2), 8390.

BKKBN. (2012). Survei Demografi Kesehatan Indonesia. Kesehatan Reproduksi Remaja.

Diah Suci Haryani, Wahyuningsih, K. H. (2016). Peran Orang Tua Berhubungan dengan Perilaku Seksual Pra Nikah Remaja di SMKN 1 Sedayu. Jurnal Ners Dan Kebidanan Indonesia, 3(3), 140. https://doi.org/10.21927/jnki.2015.3(3).140-144

Harni Andriani, Yasnani, A. D. P. (2016). Hubungan pengetahuan, akses media informasi dan peran keluarga terhadap perilaku seksual pada siswa SMK Negeri 1 Kendari tahun 2016. Jurnal Ilmiah Mahasiswa Kesehatan Masyarakat, 1(3). https://media.neliti.com/media/publications/182943-ID-hubungan-pengetahuanakses-media-informa.pdf

Istawati, R. (2017). Hubungan Keterpaparan Media Massa, Peran Teman Sebaya Terhadap Tindakan Seksual Di Sma An-Naas. Jurnal Endurance, 2(2), 124. https://doi.org/10.22216/jen.v2i2.1695

Kemenkes RI. (2015). Infodatin Situasi Kesehatan Reproduksi Remaja.

Masni, S. F. H. (2018). Determinan Perilaku Seksual Berisiko pada Remaja Makassar (Studi Kasus Santri Darul Arqam Gombara dan SMAN 6). Media Kesehatan Masyarakat Indonesia, 14(1), 68. https://doi.org/10.30597/mkmi.v14i1.3699

Nina Nirmaya Mariani, S. F. M. (2018). Peran Orang Tua, Pengaruh Teman Sebaya, Dan Sikap Berhubungan Dengan Perilaku Seksual Pranikah Pada Siswa-Siswi SMA Negeri 1 Jamblang Kabupaten Cirebon. Jurnal Care, 6(2), 116-130.

Notoatmodjo, S. (2012). Metode Penelitian Kesehatan. Jakarta: Rineka Cipta.

Parkes, A., Waylen, A., Sayal, K., Heron, J., Henderson, M., Wight, D., \& Macleod, J. (2014). Which Behavioral, Emotional and School Problems in Middle-Childhood Predict Early Sexual Behavior? Journal of Youth and Adolescence, 43(4), 507-527. https://doi.org/10.1007/s10964-013-9973-x

R, R. P. H., \& W, A. C. (2018). Hubungan antara Pengetahuan dan Paparan Media Massa dengan Perilaku Pacaran Remaja. 12(1), 60-67. https://doi.org/10.12928/kesmas.v12i1.6908

Wijayan, N. (2019). Peran teman sebaya dan media informasi terhadap perilaku seks pranikah remaja. Jurnal Health of Studies, 3(1), 53-63. 
